\title{
Development of polymorphic microsatellite markers for the genetic characterization of Knoxdavesia proteae (Ascomycota: Microascales) using ISSR-PCR and pyrosequencing
}

\begin{abstract}
Abridged title: Microsatellite development for Knoxdavesia proteae
\end{abstract}
Janneke Aylward, Léanne L. Dreyer, Emma T. Steenkamp, Michael J. Wingfield, Francois Roets

J. Aylward; L. L. Dreyer

Department of Botany and Zoology, University of Stellenbosch, Matieland 7602, South Africa

E. T. Steenkamp

Department of Microbiology and Plant Pathology, University of Pretoria, Pretoria 0002, South Africa

J. Aylward; L. L. Dreyer; E. T. Steenkamp; M. J. Wingfield; F. Roets

Department of Science and Technology (DST)/National Research Foundation (NRF) Centre of Excellence in Tree Health Biotechnology (CTHB), University of Pretoria, Pretoria 0002, South Africa

F. Roets (corresponding author)

Department of Conservation Ecology and Entomology, Stellenbosch University, Matieland 7602, South Africa. Email: fr@sun.ac.za

\begin{abstract}
Knoxdaviesia proteae is one of the first native ophiostomatoid fungi discovered in South Africa, where it consistently occurs in the infructescences of the iconic Cape Biome plant, Protea repens. Although numerous studies have been undertaken to better understand the ecology of $K$. proteae, many questions remain to be answered, particularly given its unique niche and association with arthropods for dispersal. We describe the development and distribution of microsatellite markers in K. proteae through Interspersed Simple Seqeunce Repeat-Polymerase Chain Reaction (ISSR-PCR) enrichment and pyrosequencing. A large proportion of the 31492 sequences obtained from sequencing the enriched genomic DNA were characterized by microsatellites consisting of short tandem repeats and di- and trinucleotide motifs. Seventeen percent of these microsatellites contained flanking regions
\end{abstract}


sufficient for primer design. Twenty-three primer pairs were tested, of which 13 amplified and 12 generated polymorphic fragments in K. proteae. Half of these could be transferred to the sister species, $K$. capensis. The developed markers will be used to investigate the reproductive strategy, genetic diversity and dispersal strategies of K.proteae.

Keywords: ISSR-PCR, Knoxdaviesia, Microsatellites, Ophiostomatoid, Pyrosequencing

\section{Introduction}

Knoxdaviesia proteae M.J. Wingf., P.S. van Wyk \& Marasas resides in a polyphyletic assemblage (Spatafora \& Blackwell 1994) known as the ophiostomatoid fungi (Wingfield et al. 1999), which consistently inhabits the fruiting structures (infructescences) of Protea species. All evidence suggests that this biogeographically interesting fungus is confined to the single host species, Protea repens L. (Roets et al. 2009b), where it appears as ascomatal masses on the flowers (Wingfield et al. 1988). In addition to K. proteae, eight other species belonging to this genus have been described. Of these, K. capensis M.J. Wingf. \& P.S. van Wyk and K. wingfieldii (Roets \& Dreyer) Z.W. de Beer \& M.J. Wingf. are also known from Protea species (Crous et al. 2012; Wingfield \& Van Wyk 1993), while K. serotectus (van der Linde \& Jol. Roux) Z.W. de Beer \& M.J. Wingf. and K. ubusi (van der Linde \& Jol. Roux) Z.W. de Beer \& M.J. Wingf. were isolated from declining Euphorbia ingens (E. Meyer) Boissier trees in South Africa (Van der Linde et al. 2012). Knoxdaviesia scolytodis (M. Kolařík) Z.W. de Beer \& M.J. Wingf. and K. cecropiae (M. Kolařík) Z.W. de Beer \& M.J. Wingf. colonise weevil galleries on Cecropia angustifolia Trécul trees in Costa Rica (Kolařík \& Hulcr 2009; Van der Linde et al. 2012). Knoxdaviesia suidafrikana (MorganJones \& R.C. Sinclair) Z.W. de Beer \& M.J. Wingf. and K. undulatistipes (Pinnoi) Z.W. de Beer \& M.J. Wingf. were recently transferred to Knoxdaviesia from Custingophora (De Beer et al. 2013a).

The association of $K$. proteae with $P$. repens represents an intricate symbiosis in which mites act as the primary fungal dispersers between flower heads and beetles act as the vehicles for mite dispersal (2009a; Roets et al. 2007; 2011b). Apart from its modes of dispersal, virtually nothing is known regarding the ecology of $K$. proteae. It is presumed to be a saprobe, but early occupation of infructescences suggests that it may also be able to colonize living tissues (Roets et al. 2005; F. Roets, personal observation). This, coupled with 
its high level of host specificity, suggests a more complex ecological involvement with $P$. repens.

Although a basic understanding of the ophiostomatoid fungi in Protea infructescences has emerged in recent years (2009a; Roets et al. 2005; 2011a; 2007; 2011b), very little is known regarding the population biology of these fungi, their reproductive strategies or how these contribute to issues such as dispersal and host association. For example, P. repens is a reseeder in which the infructescences open to release the seeds when their water supply is interrupted, such as after fire (Rebelo 1995). Since both plants and fungi die in these often vast fires, it remains a mystery where the ophiostomatoid fungi encountered in new $P$. repens infructescences come from. The aim of this study was, therefore to develop microsatellite markers as a tool to study the genetic diversity and dispersal biology of $K$. proteae, serving as model for other taxa within this unique ecosystem.

\section{Materials and Methods}

\section{Fungal cultures and identification}

Strains of $K$. proteae and other Knoxdaviesia species were sourced from the Culture Collection (CMW) of the Forestry and Agricultural Biotechnology Institute (FABI), University of Pretoria, South Africa. Additional $K$. proteae strains were isolated from $P$. repens infructescences from four different locations in the Western Cape Province, South Africa. Isolations were made on Malt Extract Agar (MEA; Merck, Wadeville, South Africa) supplemented with $0.04 \mathrm{~g} / \mathrm{L}$ Streptomycin Sulfate Salt (Sigma-Aldrich, Steinham, Germany) as described by Roets et al. (2006). Individual strains were isolated by sub-culturing a hyphal tip from Water Agar (15 g agar/L) to fresh MEA.

Fungal isolates were grown on MEA overlaid with sterile $3.5 \times 3.5 \mathrm{~cm}^{2}$ cellophane sheets (Product no. Z377597, Sigma-Aldrich, Steinham, Germany). Mycelium was scraped from the cellophane, placed in Eppendorf tubes and shaken vigorously with a vortex mixer in TES buffer (Möller et al. 1992), $70 \mu \mathrm{g}$ PCR grade Proteinase K (Roche Applied Science, Mannheim, Germany) and glass beads. Subsequent extraction and purification steps followed those of Möller et al. (1992). A NanoDrop ND-1000 spectrophotometer (Thermo Fisher Scientific, Wilmington, USA) was used to determine the quality and quantity of the extracted DNA. The species identity of isolates were confirmed by sequencing the ribosomal 
RNA Internal Transcribed Spacer (ITS) regions and performing BLAST (Basic Local Alignment Search Tool) searches on the NCBI nucleotide data base (www.ncbi.nlm.nih.gov). Amplification and sequencing of the ITS region was done with KAPA Taq ReadyMix (Kapa Biosystems, Inc., Boston, USA) and followed previously described methods and protocols (White et al. 1990).

\section{Microsatellite enrichment}

Knoxdaviesia proteae isolates used for microsatellite development included the ex-type strain (CMW 738) collected in the Stellenbosch area and isolate CMW 1043 from the Mossel Bay area (both in the Western Cape Province, South Africa). The ISSR-PCR (Interspersed Simple Sequence Repeat-Polymerase Chain Reaction) technique (Hantula et al. 1996; Zietkiewicz et al. 1994) was used to establish a pool of microsatellite-enriched genomic DNA. ISSR primers ISSR1 - 5'-DDB(CCA) 5 , ISSR2 - 5'-DHB(CGA) 5 , ISSR3 - 5'YHY $(\mathrm{GT})_{5} \mathrm{G}$, ISSR 4 - 5'-HVH(GTG) $)_{5}$, ISSR5 - 5'-NDB(CA) $)_{7} \mathrm{C}$, ISSR6 - 5'-NDV(CT) ${ }_{8}$, and ISSR7 - 5'-HBDB(GACA) ${ }_{4}$ were used following previously published methods (Santana et al. 2009). These primers were applied in 41 different combinations ranging from one to four primers per reaction and amplified using the Fast Start High Fidelity PCR System (Roche Applied Science, Mannheim, Germany). The $50 \mu$ reactions consisted of $5 \mu 1$ 10x buffer, $1.8 \mathrm{mM} \mathrm{MgCl} 2,2 \mu \mathrm{l}$ Dimethyl sulfoxide, $200 \mu \mathrm{M}$ of each dNTP, $0.1 \mu \mathrm{M}$ of each primer, approximately $100 \mathrm{ng}$ genomic DNA and 2.5 units of the FastStart High Fidelity Enzyme Blend. Reaction conditions were: 5 minutes at $95^{\circ} \mathrm{C}$ followed by 40 cycles of 30 seconds at $94^{\circ} \mathrm{C}, 30$ seconds at $45^{\circ} \mathrm{C}$ and 2 minutes at $72^{\circ} \mathrm{C}$, with a final extension step for 7 minutes at $72^{\circ} \mathrm{C}$.

The 41 PCR reactions were pooled and purified using the Agencourt ${ }^{\circledR}$ AMPure ${ }^{\circledR}$ XP PCR Purification kit (Beckman Coulter, Massachusetts, USA) and eluted in low TE buffer (10 mM Tris-HCl, pH 8.0; 0.1 mM EDTA). A NanoDrop ND-1000 spectrophotometer (Thermo Fisher Scientific, Wilmington, USA) and Qubit® 2.0 Fluorometer (Invitrogen, Carlsbad, California) were used to, respectively, qualify and quantify the microsatellite-enriched DNA in the sample. The final product was sent for pyrosequencing on the 454 Life Sciences/Roche GS-FLX sequencer (Roche Applied Science, Penzburg, Germany) (Margulies et al. 2005) at Inqaba Biotechnological Industries, Pretoria, South Africa. 
Microsatellite marker development

Duplicate sequences were removed from the 454 data using cdhit_454 (identity threshold = 0.98) (Niu et al. 2010). Microsatellites were identified with MSATFINDER ONLINE 2.0 (Thurston \& Field 2005) using the REGEX search engine and default search parameters to search for perfect repeats. Data were analyzed using Microsoft Office Excel 2010 (Microsoft Corp., Redmond, WA, USA).

Primers were designed with the help of MSATFINDER and PRIMER3PLUS (Untergasser et al. 2007) and sequence analysis was done with BIOEDIT 7.1.3.0 (Hall 1999). To ensure that the identified tri-nucleotide loci were not located in coding regions, the relevant pyrosequencing reads were subjected to a BLAST search using the least conservative engine, BLASTtx (www.ncbi.nlm.nih.gov). Polymorphism was assessed by amplifying and sequencing all loci in a set of $10 \mathrm{~K}$. proteae isolates. This set consisted of the ex-type strain, CMW 738, five $\mathrm{K}$. proteae strains isolated from Gouritz, two from Outeniqua Pass, and one each from Uniondale and Sir Lowry's Pass, all in the Western Cape. To test amplification of the loci in other Knoxdaviesia species, three K. capensis (CMW 974, CMW 997 and CMW 11962), two K. cecropiae (CMW 22991 and CMW 22993), one K. scolytodis (CMW 22995), three K. serotexi (CMW 34100, CMW 36767 and CMW 36768) and two K. ubusi (CMW 36769 and CMW 36770) isolates were used.

To test random association of loci, the data from the polymorphism tests were used to determine two different measures of assessing pair-wise linkage disequilibrium. Fisher's exact test was calculated with GENEPOP version 4.2 (Rousset 2008) and $\bar{r}_{d}$, the index of multilocus linkage disequilibrium, was calculated with MuLTILOCUS version 1.3b (Agapow \& Burt 2001). False discovery rate using GENPOP was avoided as recommended by Benjamini \& Yekutieli (2001).

\section{Results and Discussion}

Roche 454 sequence data

A total of 31492 sequences with an average read length of 281.2 base pairs were generated using pyrosequencing. Of these, 16820 (53\%) were unique and 5408 (17\%) had sufficient sequence data flanking the microsatellite loci for primer design. Although contigs were not constructed from our 454 data, the proportion of amplifiable sequences was slightly higher 
than the $14 \%$ noted by Santana et al. (2009), who used the same Roche 454 technology. High-throughput sequencing of an enriched pool of microsatellites, therefore, provided an immense improvement on the traditional practice of cloning and Sanger sequencing (Santana et al. 2009). The procedure was not only less laborious and time-consuming, but also afforded the advantage of being able to choose loci of interest.

\section{Identification of microsatellites}

Since microsatellites with higher-than-average repeat numbers are more likely to be polymorphic (Dettman \& Taylor 2004; Dutech et al. 2007; Goldstein \& Clark 1995), only those with repeat numbers greater than five were tested. Twenty three primer pairs were initially designed and tested. Of these, 13 loci amplified in K. proteae and 12 generated polymorphic fragments (Table 1). The other was a compound microsatellite, $(\mathrm{ACAG})_{6-7}(\mathrm{C})_{\mathrm{n}}$, and was discarded as its mutational mechanism may differ significantly from that of perfect repeats. The number of alleles detected ranged from 2 to 9 with a mean of $4.75 \pm 0.55-$ similar to the average allele number of $5.4 \pm 0.4$ reported for fungi (Dutech et al. 2007). Neither Fisher's exact test nor the $\overline{\mathrm{r}}_{\mathrm{d}}$ value indicated significant pairwise linkage after performing the linkage disequilibrium tests.

\section{Cross-species transferability}

In the three $K$. capensis isolates, six of the 12 microsatellite markers amplified in isolates CMW 997 and CMW 19962 and four in CMW 974. All six markers were polymorphic between $K$. proteae and $K$. capensis and polymorphism could also be detected within $K$. capensis for loci Ti-4, Ti-6 and T5. The cross-species transferability rate was higher than expected based on previous fungal studies. For example, in a survey of fungal studies Dutech et al. (2007) reported a transferability rate of approximately $34 \%$. However, this high rate of marker transferability was not surprising, as $K$. capensis is phylogenetically most closely related to $K$. proteae, and these two species group separately from other Knoxdaviesia species in phylogenetic trees (De Beer et al. 2013b; Wingfield et al. 1999).

\section{Distribution of microsatellites in Knoxdaviesia proteae 454 sequence data}

Microsatellite distribution was described based on the results of the Multipass search implemented in MSatFinder Online version 2.0 (Thurston \& Field 2005). Similar results were generated using the other MSatFinder engines, but Multipass allowed detection of 
Table 1 Polymorphic microsatellites developed for Knoxdaviesia proteae

\begin{tabular}{|c|c|c|c|c|c|c|c|c|c|}
\hline \multirow{2}{*}{ Locus } & \multirow{2}{*}{ Motif } & \multirow{2}{*}{$\begin{array}{c}\text { Genbank } \\
\text { accession }\end{array}$} & \multirow{2}{*}{$\begin{array}{l}\text { Primer } \\
\text { names }\end{array}$} & \multirow{2}{*}{ Primer sequences ( $\left.5^{\prime}-3^{\prime}\right)$} & \multirow{2}{*}{$\begin{array}{c}\text { Fluorescent } \\
\text { tag }\end{array}$} & \multirow{2}{*}{ Size range } & \multicolumn{2}{|c|}{ Alleles } & \multirow{2}{*}{ Transferable } \\
\hline & & & & & & & Gouritz $^{a}$ & Total $^{\mathrm{b}}$ & \\
\hline D2 & $(\mathrm{tc})_{16}$ & KF924611 & $\begin{array}{l}\text { KX1-1 } \\
\text { KX1-2 }\end{array}$ & $\begin{array}{c}\text { GAGACATACTGGACTGTACACATTCAT } \\
\text { CGTCCTGTAGTGGCTATCCTG }\end{array}$ & $\begin{array}{l}\mathrm{VIC} \\
-\end{array}$ & $107-115$ & 4 & 9 & - \\
\hline Ti-2 & $(\mathrm{ctt})_{16}$ & KF924612 & $\begin{array}{l}\mathrm{KX} 2-1 \\
\mathrm{KX} 2-2\end{array}$ & $\begin{array}{l}\text { TGTCGGGTCCTGTGTAACTG } \\
\text { CGGATTGTATCAGTTGTCCTCA }\end{array}$ & $\begin{array}{l}\text { PET } \\
-\end{array}$ & $108-144$ & 4 & 8 & - \\
\hline Ti-3 & $(\mathrm{ctt})_{13}$ & KF924613 & $\begin{array}{l}\mathrm{KX} 3-1 \\
\mathrm{KX} 3-2\end{array}$ & $\begin{array}{l}\text { CGGGACTCCACTCTCTCAAG } \\
\text { CCGGACTCTAGACGTTGAGG }\end{array}$ & $\begin{array}{l}\text { VIC } \\
-\end{array}$ & $173-200$ & 1 & 3 & - \\
\hline Ti-4 & $(\mathrm{gtc})_{12}$ & KF924614 & $\begin{array}{l}\text { KX4-1 } \\
\text { KX4-2 }\end{array}$ & $\begin{array}{l}\text { AAGAAAAGCCAAGGGGAGAG } \\
\text { ACTTACAGGCCAGGACCACA }\end{array}$ & $\begin{array}{l}\text { NED } \\
-\end{array}$ & $166-184$ & 2 & 5 & $K$. capensis $^{\mathrm{c}}$ \\
\hline Ti-5 & $(\mathrm{cag})_{11}$ & KF924615 & $\begin{array}{l}\text { KX5-1 } \\
\text { KX5-2 }\end{array}$ & $\begin{array}{l}\text { ACGACAGCAGATGCATGAAG } \\
\text { GCTGTCTTGCTGCTGAACTG }\end{array}$ & $\begin{array}{l}\text { NED } \\
-\end{array}$ & $115-127$ & 4 & 5 & - \\
\hline Ti-6 & $(\operatorname{acc})_{9}$ & KF924616 & $\begin{array}{l}\text { KX6-1 } \\
\text { KX6-2 }\end{array}$ & $\begin{array}{l}\text { CAAAATGGTGCCCTATGACC } \\
\text { ACAAGCCAGAGTTTGGAGGA }\end{array}$ & $\begin{array}{c}\text { 6-FAM } \\
-\end{array}$ & 189-198 & 3 & 4 & K. capensis ${ }^{\mathrm{c}}$ \\
\hline
\end{tabular}




\begin{tabular}{|c|c|c|c|c|c|c|c|c|c|}
\hline Ti-7 & $(\mathrm{ctt})_{9}$ & KF924617 & $\begin{array}{l}\text { KX7-1 } \\
\text { KX7-2 }\end{array}$ & $\begin{array}{l}\text { AGACGCTTCCATCTCGTTTC } \\
\text { GGAGATGGCGAGAGAAGTTG }\end{array}$ & $\begin{array}{c}\text { 6-FAM } \\
-\end{array}$ & $96-108$ & 2 & 3 & K. capensis \\
\hline $\mathrm{T} 2$ & $(\operatorname{atgg})_{7}$ & KF924618 & $\begin{array}{l}\text { KX8-1 } \\
\text { KX8-2 }\end{array}$ & $\begin{array}{l}\text { GACGACGATCACAGGACGAC } \\
\text { CAAGCCCTCAAAGTTGCTTC }\end{array}$ & $\begin{array}{c}\text { 6-FAM } \\
-\end{array}$ & $104-116$ & 2 & 4 & K. capensis \\
\hline $\mathrm{T} 3$ & $(\operatorname{agtg})_{8}$ & KF924619 & $\begin{array}{l}\text { KX9-1 } \\
\text { KX9-2 }\end{array}$ & $\begin{array}{l}\text { TGAGATTGCGAGTGTGCTTC } \\
\text { GGTGTGCATCAATTGTTCGT }\end{array}$ & $\begin{array}{l}\text { VIC } \\
-\end{array}$ & $100-132$ & 2 & 4 & - \\
\hline $\mathrm{T} 4$ & $(\operatorname{attc})_{6}$ & KF924620 & $\begin{array}{l}\text { KX10-1 } \\
\text { KX10-2 }\end{array}$ & $\begin{array}{l}\text { CCCCATCAGTTCACTGACATC } \\
\text { GACCACAGTTGGGAAAATCG }\end{array}$ & $\begin{array}{l}\text { PET } \\
-\end{array}$ & $183-195$ & 4 & 5 & K. capensis \\
\hline T5 & $(\operatorname{agtg})_{7}$ & KF924621 & $\begin{array}{l}\text { KX11-1 } \\
\text { KX11-2 }\end{array}$ & $\begin{array}{l}\text { AGAGAGCCTTCCCAAAAGGT } \\
\text { GCGAAAGGGAACATAAATCG }\end{array}$ & $\begin{array}{c}\text { 6-FAM } \\
-\end{array}$ & $185-189$ & 2 & 2 & $K$. capensis $^{\mathrm{c}}$ \\
\hline T6 & $(\operatorname{ctg} t)_{16}$ & KF924622 & $\begin{array}{l}\text { KX12-1 } \\
\text { KX12-2 }\end{array}$ & $\begin{array}{l}\text { GGGCAGAACCGTTCATATTC } \\
\text { AACCCTGCGTCAGACACC }\end{array}$ & VIC & $183-231$ & 4 & 5 & - \\
\hline
\end{tabular}

${ }^{a}$ Alleles from the 5 strains isolated from the Gouritz area

${ }^{\mathrm{b}}$ Alleles from all 10 strains used to test polymorphism

${ }^{\mathrm{c}}$ Polymorphic in K. capensis 


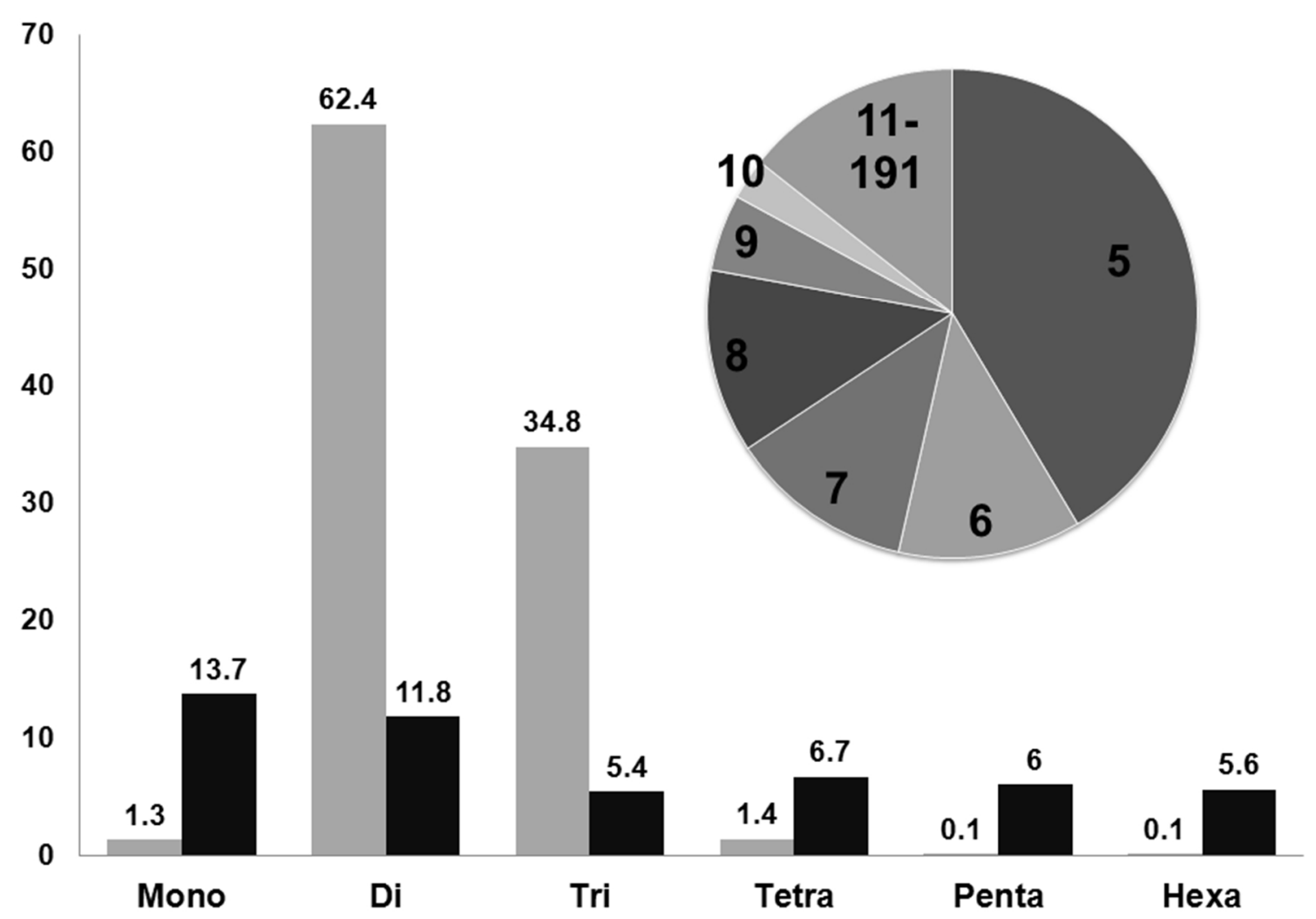

Fig. 1 Distribution of microsatellite classes and tandem repeat units in the 454 data. The histogram indicates the percentage occurrence (grey bars) and the mean number of tandem repeats (black bars) observed for each microsatellite class. Standard errors are too small to be displayed on the graph. The pie chart displays the prevalence (in \%) of the different tandem repeat numbers (shown on chart). Tandem repeat numbers 6, 7 and 8 are in equal proportion and 11 to 191 are merged

additional microsatellite loci in all classes except the mono-nucleotides. For these analyses, duplicate sequences were excluded at a cdhit_454 threshold of 0.95 .

Although the microsatellite enrichment strategy employed in this study might have skewed the observed distribution of these motifs in $K$. proteae, our results are consistent with those for fungi. For example, studies considering whole-genome sequences (Karaoglu et al. 2005; Katti et al. 2001; Lim et al. 2004) have shown that fungal microsatellites tend to be short and that mono-, di- and tri-nucleotide motifs predominate. Di- and tri-nucleotides were encountered frequently in our data, while mono-nucleotide motifs comprised only $1.3 \%$ of the identified microsatellites (Fig. 1). Such frequencies have also been reported following analysis of an ISSR-PCR enriched library for Fusarium circinatum Nirenberg \& O'Donnell 
(Santana et al. 2009), suggesting that the relatively few mono-nucleotide microsatellites observed in this study might be a consequence of the specific enrichment method used.

Although tandem repeat numbers of up to 191 were observed, short repeats were most common (Fig. 1). More than $40 \%$ of microsatellites consisted of 5 tandem repeats and 86.7 $\%$ had 5-10 repeats. This is roughly the same as reported by Lim et al. (2004), who found that $90 \%$ of their dataset was comprised of microsatellites with 5-7 repeat units. As expected and observed in previous studies (Karaoglu et al. 2005; Santana et al. 2009), the average tandem repeat number of the microsatellites decreased as the motif complexity increased. This may be due to lower mutation rate and therefore lower polymorphism in long motifs (Chakraborty et al. 1997; Kruglyak et al. 1998), as well as a bias towards contraction mutations in large microsatellite alleles (Xu et al. 2000).

\section{Conclusions}

This study is the first to develop microsatellite markers for a species of Knoxdaviesia and also the first to apply microsatellite enrichment coupled with pyrosequencing to ophiostomatoid fungi. The 12 polymorphic markers developed here will be applied to investigate the genetic diversity and dispersal of this arthropod-vectored fungus within the Cape Floristic Region of South Africa. Half of the markers also have the potential to be used to study the closely related $K$. capensis, establishing an opportunity for comparison of these ecologically similar fungi.

\section{Acknowledgements}

We thank the National Research Foundation (NRF) and the Department of Science and Technology (DST)/NRF Centre of Excellence in Tree Health Biotechnology (CTHB) for financial support and theWestern Cape Nature Conservation Board for issuing the necessary collecting permits.

\section{References}

Agapow P-M, Burt A (2001) Indices of multilocus linkage disequilibrium. Molecular Ecology Notes 1, 101-102. 
Benjamini Y, Yekutieli D (2001) The Control of the False Discovery Rate in Multiple Testing under Dependency. The Annals of Statistics 29, 1165-1188.

Chakraborty R, Kimmel M, Stivers DN, Davison LJ, Deka R (1997) Relative mutation rates at di-, tri-, and tetranucleotide microsatellite loci. Proceedings of the National Academy of Sciences 94, 1041-1046.

Crous PW, Summerell BA, Shivas RG, et al. (2012) Fungal Planet description sheets: 107127. Persoonia 28, 138-182.

De Beer ZW, Seifert KA, Wingfield MJ (2013a) A nomenclature for ophiostomatoid genera and species in the Ophiostomatales and Microascales. In: Ophiostomatoid fungi: expanding frontiers (eds. Seifert KA, de Beer ZW, Wingfield MJ), pp. 245-322. CBS Biodiversity Series.

De Beer ZW, Seifert KA, Wingfield MJ (2013b) The ophiostomatoid fungi: their dual position in the Sordariomycetes. In: Ophiostomatoid fungi: expanding frontiers (eds. Seifert KA, de Beer ZW, Wingfield MJ), pp. 1-20. CBS Biodiversity Series.

Dettman JR, Taylor JW (2004) Mutation and Evolution of Microsatellite Loci in Neurospora. Genetics 168, 1231-1248.

Dutech C, Enjalbert J, Fournier E, et al. (2007) Challenges of microsatellite isolation in fungi. Fungal Genetics and Biology 44, 933-949.

Goldstein DB, Clark AG (1995) Microsatellite variation in North American populations of Drosophila melanogaster. Nucleic Acids Research 23, 3882-3886.

Hall TA (1999) BioEdit: a user-friendly biological sequence alignment editor and analysis program for Windows 95/98/NT. Nucleic Acids Symp Ser 41, 95-98.

Hantula J, Dusabenyagasani M, Hamelin RC (1996) Random amplified microsatellites (RAMS) - a novel method for characterizing genetic variation within fungi. European Journal of Forest Pathology 26, 159-166.

Karaoglu H, Lee CMY, Meyer W (2005) Survey of Simple Sequence Repeats in Completed Fungal Genomes. Molecular Biology and Evolution 22, 639-649.

Katti MV, Ranjekar PK, Gupta VS (2001) Differential Distribution of Simple Sequence Repeats in Eukaryotic Genome Sequences. Molecular Biology and Evolution 18, 1161-1167.

Kolařík M, Hulcr J (2009) Mycobiota associated with the ambrosia beetle Scolytodes unipunctatus (Coleoptera: Curculionidae, Scolytinae). Mycological Research 113, 44-60.

Kruglyak S, Durrett RT, Schug MD, Aquadro CF (1998) Equilibrium distributions of microsatellite repeat length resulting from a balance between slippage events and point mutations. Proceedings of the National Academy of Sciences 95, 10774-10778.

Lim S, Notley-McRobb L, Lim M, Carter DA (2004) A comparison of the nature and abundance of microsatellites in 14 fungal genomes. Fungal Genetics and Biology 41, $1025-1036$.

Margulies M, Egholm M, Altman WE, et al. (2005) Genome sequencing in microfabricated high-density picolitre reactors. Nature 437, 376-380.

Möller EM, Bahnweg R, Sandermann H, Geiger HH (1992) A simple and efficient protocol for isolation of high molecular weight DNA from filamentous fungi, fruit bodies, and infected plant tissues. Nucleic Acids Research 20, 6115-6116.

Niu B, Fu L, Sun S, Li W (2010) Artificial and natural duplicates in pyrosequencing reads of metagenomic data. BMC Bioinformatics 11, 187.

Rebelo T (1995) Proteas: A field guide to the Proteas of Southern Africa Fernwood Press, Vlaeberg, South Africa. 
Roets F, Crous PW, Wingfield MJ, Dreyer LL (2009a) Mite-mediated hyperphoretic dispersal of Ophiostoma spp. from the Infructescences of South African Protea spp. Environmental Entomology 28, 143-152.

Roets F, de Beer ZW, Dreyer LL, et al. (2006) Multi-gene phylogeny for Ophiostoma spp. reveals two new species from Protea infructescences. Studies in Mycology 55, 199212.

Roets F, Dreyer LL, Crous PW (2005) Seasonal trends in colonisation of Protea infructescences by Gondwanamyces and Ophiostoma spp. South African Journal of Botany 71, 307-311.

Roets F, Theron N, Wingfield MJ, Dreyer LaL (2011a) Biotic and abiotic constraints that facilitate host exclusivity of Gondwanamyces and Ophiostoma on Protea. Fungal Biology 116, 49-61.

Roets F, Wingfield MJ, Crous PW, Dreyer LL (2007) Discovery of Fungus-Mite Mutualism in a Unique Niche. Environmental Entomology 36, 1226-1237.

Roets F, Wingfield MJ, Crous PW, Dreyer LL (2009b) Fungal radiation in the Cape Floristic Region: An analysis based on Gondwanamyces and Ophiostoma. Molecular Phylogenetics and Evolution 51, 111-119.

Roets F, Wingfield MJ, Wingfield BD, Dreyer LL (2011b) Mites are the most common vectors of the fungus Gondwanamyces proteae in Protea infructescences. Fungal Biology 115, 343-350.

Rousset F (2008) Genepop'007: a complete re-implementation of the genepop software for Windows and Linux. Mol Ecol Resour 8, 103-106.

Santana QC, Coetzee MPA, Steenkamp ET, et al. (2009) Microsatellite discovery by deep sequencing of enriched genomic libraries. BioTechniques 46, 217-223.

Spatafora JW, Blackwell M (1994) The polyphyletic origins of ophiostomatoid fungi. Mycological Research 98, 1-9.

Thurston MI, Field D (2005) Msatfinder: detection and characterisation of microsatellites. Distributed by the authors at http://www.genomics.ceh.ac.uk/msatfinder/. CEH Oxford, Mansfield Road, Oxford OX1 3SR.

Untergasser A, Nijveen H, Rao X, et al. (2007) Primer3Plus, an enhanced web interface to Primer3. Nucleic Acids Research 35, W71-W74.

Van der Linde JA, Six DL, Wingfield MJ, Roux J (2012) New species of Gondwanamyces from dying Euphorbia trees in South Africa. Mycologia 104, 574-584.

White TJ, Bruns T, Lee S, Taylor JW (1990) Amplification and direct sequencing of fungal ribosomal RNA genes for phylogenetics. In: PCR protocols: a guide to methods and applications (eds. Innis MA, Gelfand DH, Sninsky JJ, White TJ), pp. 315-322. Academic Press, San Diego, California.

Wingfield BD, Viljoen CD, Wingfield MJ (1999) Phylogenetic relationships of ophiostomatoid fungi associated with Protea infructescences in South Africa. Mycological Research 103, 1616-1620.

Wingfield MJ, Van Wyk PS (1993) A new species of Ophiostoma from Protea infructescences in South Africa. Mycological Research 97, 709-716.

Wingfield MJ, Wyk PSV, Marasas WFO (1988) Ceratocystiopsis proteae sp. nov., with a new anamorph genus. Mycologia 80, 23-30.

$\mathrm{Xu}$ X, Peng M, Fang Z (2000) The direction of microsatellite mutations is dependent upon allele length. Nature Genetics 24, 396-399.

Zietkiewicz E, Rafalski A, Labuda D (1994) Genome Fingerprinting by Simple Sequence Repeat (SSR)-Anchored Polymerase Chain Reaction Amplification. Genomics 20, 176-183. 